\title{
Community health workers in rural Punjab, India: analyzing their role, expectations and challenges
}

\author{
Niharika Mahajan and Baljit Kaur \\ Punjab School of Economics, Guru Nanak Dev University, Amritsar, India
}

\begin{abstract}
Purpose - This study aimed to analyze the role of community health workers (CHWs) called accredited social health activists (ASHAs) in improving maternal health outcomes in the rural community of Punjab, India. The study also examined the expectations of these workers from the community and identified the problems faced by them in carrying out their roles.

Design/methodology/approach - Using multistage sampling, a total of 28 villages were selected from seven districts of Punjab, and from these selected villages, a total of 57 ASHAs working as the interface between the rural community and the public health system and 420 women who had delivered a baby were interviewed. Findings - Desire to earn money was the most prominent reason for joining the community work program, but ASHAs felt overburdened and underpaid compared to their work commitments. Not only was the incentive paid to these workers was insufficient and irregular but they also suffered at the hands of medical staff at public hospitals.

Originality/value - While exploring the problems experienced by the CHWs, this study recommends opting for a mix of monetary and nonmonetary incentives for acknowledging the work of CHWs. The study is the first of its kind for the state of Punjab battling with a worsening maternal mortality rate (MMR).
\end{abstract}

Keywords Community health workers, Incentives, India

Paper type Research paper

\section{Introduction}

Using community health workers (CHWs) for rendering basic health services and filling in the gaps created by the shortage of human resources,particularly in low-income settings, is not a novel phenomenon. As defined in the report of a World Health Organization (WHO) Study Group, CHWs "should be members of the community where they work, should be selected by the communities, should be answerable to the communities for their activities, should be supported by health system but not necessarily a part of its organization and have shorter training than professional workers" [1]. The earliest large-scale community health worker program was in China called "Farmer Scholars" whereby illiterate farmers were trained in the provision of the vaccination against smallpox and other such diseases, first aid and talks on health education; cataloging births and deaths and promoting the cleaning of wells. The ineffectiveness of the Western medical model of using trained health personnel to deal with the health needs of the rural and poor populace of developing countries manifested the importance of the CHW program. The 1970s and 1980s witnessed an increase in CHW programs in a number of countries fueled by the Alma-Ata Declaration.

\footnotetext{
(C) Niharika Mahajan and Baljit Kaur. Published in Journal of Health Research. Published by Emerald Publishing Limited. This article is published under the Creative Commons Attribution (CC BY 4.0) licence. Anyone may reproduce, distribute, translate and create derivative works of this article (for both commercial and non-commercial purposes), subject to full attribution to the original publication and authors. The full terms of this licence may be seen at http://creativecommons.org/licences/by/4.0/ legalcodea

The authors would like to thank the University Grants Commission, India for providing a NET-JRF Grant.
}

Community health workers in rural Punjab

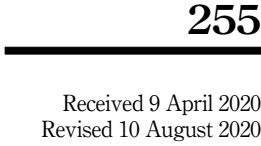
Accepted 17 September 2020 
JHR

36,2

However, during the 1980s CHW programs suffered primarily because of the oil crisis of the 1970s and the resulting debt crisis in the developing world forcing such countries to adopt stringent structural adjustment policies promulgated by the World Bank. The setback was further aggravated by "inadequate training, insufficient remuneration or incentives for CHWs and a lack of supervision and logistical support for supplies and medicines" in developing countries [2]. CHW programs captured the renewed interest of the global community in the wake of prevailing health systems falling by the wayside to meet the global commitments toward health and WHO advocating "task shifting" and training of these workers to relieve overstressed healthcare systems [2-4].

The Government of India introduced the "Accredited Social Health Activist (ASHA)" program under the broad remit of the National Rural Health Mission (NRHM) in 2005 against the background of high rates of infant mortality and maternal mortality, the paucity of trained human resources at the village level and incompetency of auxiliary nurse midwives to furnish health services at the doorstep; the program being the largest of its kind in the world $[5,6]$. An ASHA is a woman resident of the village with educational qualifications up to tenth standard and ideally in the age group of 25-45 years. The criterion for educational qualification could be retracted in the absence of a suitable candidate with this qualification [7]. Receiving 23 days of training at the time of induction, these activists are paid performance-based incentives. The NRHM advocated one ASHA for every 1,000 of the population and at the time of its introduction, 400,000 female workers were engaged as ASHAs [5].

At present, about 970,676 ASHA workers are interlinking the community and the public health system in the country [6]. The roles and responsibilities of ASHAs include identifying and registering new pregnancies, births and deaths; mobilizing counsel and support for the community in demanding and seeking health services; identifying, managing or referring diseased cases; supporting health service delivery through home visits, first-aid, immunization sessions and camps and maintaining data and participating in community-level health planning [8]. Punjab, one of the richest states of India, is also one of the worst performers on the maternal mortality rate (MMR) [9, 10]. The last improvement in MMR was achieved by the state in 2014-2016 when MMR fell from 141 in 2011-2013 to 122 in 2014-2016. Even though India has been successful in securing a decrease in the MMR from 122 to 113 during 2015-2017 and 2016-2018, Punjab has been among the poor performers with an increase of seven points in MMR from 122 in 2015-2017 to 129 in 20162018 [10].

The role of CHWs who take healthcare to the doorstep in addressing the probable causes of such increases such as anemia during pregnancy, failure of the migratory population in reaching health facilities, reliance on self-made god-men among certain sections of society, etc. then becomes crucial [11].

The study has tried to analyze the role of ASHAs in improving maternal health outcomes along with examining their expectations from community work and problems faced by them in the rural community of Punjab.

\footnotetext{
Methodology

Out of the 22 districts of Punjab, a selection of seven districts was made accounting for $50 \%$ of the total rural reproductive female population.

Using multistage sampling, two blocks from each district and two villages from each block were randomly selected in the second and third stages. Using pretested interview schedules, from these 28 villages, a total of 57 ASHAs who were working as an interface between the health system and these communities were willing to participate in the study,
} 
and 420 ever-married women (15 from each village) who had delivered in one year preceding the date of the survey were questioned. Descriptive statistics and Henry Garrett Ranking were used to analyze the data.

\section{Ethical consideration}

The study was ethically approved by the Institutional Ethics Committee of Guru Nanak Dev University, India (Ref. No.: 21/HG/2020).
Community health workers in rural Punjab

\section{Results}

Before studying the role, expectations and problems of the community workers, the socioeconomic characteristics of the ASHA workers surveyed in the study are presented in Table 1.

The majority of these workers were in the age group of 25-45 and met the educational eligibility criteria. The maximum share of ASHA workers $(42.1 \%)$ had a family income in the range of US\$133.76-200.64, followed by over 31\% of the workers in the range of US\$ 66.88 133.76 and $12.3 \%$ workers in the range of US $\$ 200.64-267.51$.

For a higher share of workers $(33.3 \%)$, the monthly incentive ranged from US $\$ 26.75$ to US $\$ 33.44$. The minimum incentive reported by an ASHA worker in the study was US $\$ 16.05$, and the maximum incentive reported was US\$ 80.25.

In total, three ASHA workers reported being the sole breadwinners of their family, and in the absence of fixed remuneration, they were finding it difficult to make ends meet. It is observed that the maximum number of ASHAs belonged to the marginalized communities of the society with the share of scheduled castes being $56.1 \%$. Classification based on religion revealed that the majority of workers practiced Sikhism. The average population being served by these workers in the 28 villages covered under the present study was 1350.

In the arena of maternal health, the specific roles of ASHAs could be listed as identifying the pregnant woman and facilitating her registration for antenatal care; helping the woman in receiving at least three antenatal checkups including tetanus toxoid injections and iron and folic tablets; identifying a functional government health facility or private health facility accredited by the government for referral and delivery; counseling for institutional delivery; escorting the woman to a preidentified health facility and staying till the woman was discharged and making postnatal visits to the mother within seven days of delivery to track the mother's health and facilitate in obtaining care, whenever and wherever necessary [12].

Of the 420 delivered women questioned as a part of the study, more than $83 \%$ registered their pregnancies within the first three months with their respective ASHA workers. About $83 \%$ of the pregnant women were assisted by an ASHA in their area regarding birth preparedness, while 93.6 and $96 \%$ of respondents were counseled on the benefits of safe delivery and immunization of the newborn. However, counseling received on feeding the newborn and family planning as reported by the women surveyed was inadequate. On average, ASHAs visited pregnant women thrice a month during the tenure of pregnancy.

More than $96 \%$ of respondents had availed themselves of at least four antenatal checkups and over $99 \%$ had received one tetanus toxoid injection. The full antenatal coverage (comprising at least four antenatal checkups, one tetanus toxoid injection and 100 iron-folic acid tablets or equivalent syrup) was $68.8 \%$. Of the 420 women who had delivered, 403 delivered in a health facility with 208 such women reported being guided by ASHA workers to deliver in a health facility. 
Individual characteristics

Age (years)

$\leq 25$

25-45

Education

Primary

Upper primary

Secondary

Senior secondary

University graduate and above

Economic status of ASHA

Family income (US\$)

$\leq 66.88^{*}$

66.88-133.76

133.76-200.64

200.64-267.51

Incentive received (US\$)

$33.44-40.13$

Social and community identity of ASHA workers

Caste

General

Scheduled caste

Other backward classes

\section{Religion}

Hinduism

Other

Table 1.

Average population served per ASHA

Note(s): *US\$ 1 = INR 74.76 as of July, 31, 2020

In the case of 207 women, an ASHA worker was present at the time of delivery in the health facility. Postnatal checkup within 24 hours of delivery was received by $95.7 \%$ of recently delivered women. However, only around one-fourth of these postpartum mothers $(25.9 \%)$ received the recommended additional number of postnatal checkups. One of the roles of an ASHA is paying visits to a postpartum mother, and all the respondents reported receiving such visits, other than those who had gone to their maternal home after giving birth.

The authors tried to get information on the expectations of these workers from their work by soliciting them for the reasons why they joined this community work. They were presented with five reasons, namely the desire to earn a monetary incentive, opportunity to gain exposure, to improve village health facilities, social prestige related to the job and free time at their disposal; and were asked to rank them on the scale of one to five as per their relevance. 
Using the technique of Henry Garrett ranking and the responses received from these 57 health activists in, the reasons were ranked as shown in Table 2.

In Table 2, the desire to earn a monetary incentive emerged as the most important reason for joining the community work. The second most important reason was to improve the health facilities of the village, while the free time at the disposal of these workers before joining the community work emerged as the third important reason. The opportunity to get more exposure as a result of this work and the social prestige associated emerged as the least important reasons.

The average incentive earned by ASHA workers was US $\$ 35.58$, and the average hours of work were $17 \mathrm{~h}$ a week, making it approximately $68 \mathrm{~h}$ or 8.5 days of work in a month. Over $31 \%$ of the ASHA workers complained of late receipt of financial incentive, and 43 out of 57 ASHA workers were not satisfied with the amount they were receiving.

Various concerns were highlighted by these workers including their discontent with the amount of financial incentive compared with ever-increasing work responsibilities. Other than conducting the tasks set for them under the NRHM (now National Health Mission), they had to fulfill the responsibilities of other health workers. ASHAs complained of the compulsion to spend out of their pockets to purchase stationery items as they were provided with only a register and a diary from the government. Since the desire to make monetary incentives emerged as the most important reason for joining the community work, limited incentives compared to the efforts made it difficult for them to meet their daily household expenses. In certain scenarios, they were required to spend their own money to take pregnant women in their community to the hospital. Given the discontentment of these workers regarding the monetary incentive, the hope to secure a permanent government job with a fixed salary was driving these community workers to continue to work. In the event of continuity of these irregular and incongruous incentives, more than $40 \%$ of the workers were ready to leave the community work if they come across any other opportunity which helped them to earn more.

Other than the meager incentive, ill-treatment at the hands of public hospital staff that they faced almost every day added to their miseries. This not only hindered them from fulfilling their responsibilities but also created a barrier for the pregnant women who were contemplating utilizing public health facilities. It was reported by ASHA workers that some government hospitals were so infamous for their mistreatment that when the pregnant mother was referred to such a hospital, the family preferred to opt for expensive private facilities rather than enduring abusive behavior at the government hospital. The result is that the delivery took place in a private hospital, and all the efforts of the ASHA worker in convincing the pregnant lady and her family regarding the benefits of delivering at a government hospital were in vain. Due to the nonavailability of doctors at public hospitals at night time, pregnant women were referred to far-off places, and it became difficult for these workers to escort them. When taking pregnant women to hospitals for delivery, especially

\begin{tabular}{llcc}
\hline Reasons & $\begin{array}{l}\text { Total } \\
\text { score }\end{array}$ & $\begin{array}{c}\text { Mean } \\
\text { score }\end{array}$ & $\begin{array}{c}\text { Rank from Garrett } \\
\text { Ranking }\end{array}$ \\
\hline Desire for monetary incentive & 3685 & 64.64 & 1 \\
Opportunity to get more exposure & 2576 & 45.19 & 4 \\
Improving health facilities in the village & 2879 & 50.50 & 2 \\
community & & & 5 \\
Social prestige & 2529 & 44.36 & 3 \\
Nothing to do & 2581 & 45.28 & 5
\end{tabular}

Source(s): Authors' own calculations

\section{Community health workers in rural Punjab}

259

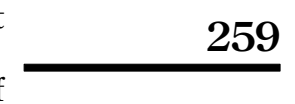


JHR

36,2

during irregular hours, ASHAs complained of the absence of any separate rooms where they could sit and rest. Another issue brought up by ASHA workers was the long queues at government scanning facilities. Most of the government hospitals offer scanning facilities for a limited period in the day, and the result is long waiting lines with hordes of other patients. It became difficult for the pregnant women to go through such long queues, and they finally ended up utilizing private diagnostic facilities.

The government of India introduced a conditional cash incentive program, Janani Suraksha Yojana (JSY) in 2005, whereby a monetary incentive is paid to the women who meet the eligibility criteria. The existing literature on JSY highlights that though the scheme has been successful in taking pregnant women to hospitals, the payment of incentives has been appalling [13-15]. Among the ever-married women questioned, 242 women met the eligibility criteria, but the incentive payment was received by only 76 women. In the absence of receipt of the incentive, these community workers become the soft targets and were often blamed.

\section{Discussion}

The present study has tried to analyze the role played by these activists in improving the maternal health outcomes among the sampled women, along with examining their expectations and the problems faced by them. In total, $83 \%$ of the recently delivered women had registered their pregnancy with the respective ASHA worker within the first three months, and $68.8 \%$ of the women had received full antenatal checkups. The institutional delivery rate in the study was $96 \%$.

Regarding the role of ASHAs to counsel the women on birth preparedness, need for safe delivery, baby's immunization, feeding the newborn and family planning, it was observed in the study that on the first three parameters, the performance of the ASHA was appreciable. In the case of feeding practices, it was generally believed that such advice comes from the elderly female member of the family or the doctor, and in case of family planning, ASHAs hesitated from counseling the women without a son since family planning in rural areas is still guided by the preference to have a son. As per the fourth round of the National Family Health Survey, the full antenatal coverage in Punjab has increased from 11.8 to $30.7 \%$ over the period between 2005-2006 and 2015-2016, and ASHAs have played an ambitious role in securing this increase [16]. There has been an increase in the utilization of prepartum, intrapartum and postpartum services post the ASHA program in India $[17,18]$. Of the three components of maternal care, the least utilized component in the present study was postnatal care.

The majority of respondents, after getting discharged from the hospital, did not seek recommended postnatal care visits. In such a scenario, the visits of ASHAs to the postpartum mothers helped in ensuring the well-being of the mothers and the newborns. Studying the expectations of these activists from their work is important since these expectations serve as the basis for motivation, which in turn influences their recruitment, retention and performance. Desire to earn followed by improving the health facilities in the community have been the major reasons for these CHWs to join work in the present study.

However, the reality stands in stark contradiction to the expectations. In the present study, the average incentive of US\$ 35.58 and average working hours of 8.5 days a month implies that the incentive is not commensurate with the existing minimum wage rate for unskilled workers. The existing minimum wage rate for unskilled workers in India is US\$ 4.29 per day while the recommended wage rate is US\$ 5.02 [19].

Since the majority of these workers hail from poor socioeconomic backgrounds, the limited amount of incentive results in displeasure, and their exasperation level can be judged by the words of an ASHA worker "even the laborer under the Mahatma Gandhi National Rural Employment Guarantee Act makes more money than us" (the Mahatma Gandhi 
National Rural Employment Guarantee Act provides wage employment of an unskilled nature of at least 100 days in a fiscal year).

The desire to contribute toward the community's well-being by improving the health facilities of the village constitutes an important intrinsic motivation factor but evidence shows that it cannot serve to recompense demotivation resulting from the low financial reward [20].

Although the aspiration to serve the community and prestige partly contributes to the motivation of these workers, it is necessarily boosted by the monetary compensation [21].

For many CHWs, this limited remuneration is the only access to money [22]. Saprii et al. [23] reported that for ASHA workers included in their study, the ASHA program provided them with a source of employment along with a chance to work up their social status and to serve the community.

The displeasure of CHWs with the amount, inconsistency and irregularity of incentives has been reported by several studies. ASHAs lamented receiving incentives for only five tasks out of the 20, which they were performing while the remaining being completed without payment [24].

These workers remain on duty all the time, performing over 73 different functions, and are responsible for the implementation of almost all government programs on health [25]. Over the years, the country has witnessed protests from different sections of ASHA workers, raising their demand for a regular job with a fixed salary. Monetary incentives are important for the retention of CHWs struggling to support their families [26, 27].

The study also highlights how the callous behavior of public health staff hinders their functioning and also drives away expectant women approaching them whose consequences are borne by these community workers. Preferential treatment at a health facility is an important nonmaterial incentive that helps in sustaining the motivation to work [20]. ASHAs greatly rely on the JSY scheme because out of the various tasks allocated to these workers, referring pregnant women during pregnancy and escorting them for delivery at government hospitals provides an acceptable range of compensation compared to other tasks that are either poorly or not incentivized at all [23].

In the absence of a fixed salary, the incentive-based model of paying CHWs result in an uneven focus on certain activities (e.g. institutional delivery and immunization) that are associated with higher incentives and neglect others that are not [23, 28]. Using monetary and nonmonetary incentives to keep up the morale of these workers is well established in the literature, and the same has been adopted by many states in India. On the one hand, certain states are providing a fixed monthly honorarium to their workers, on the other nonmonetary incentive in the form of social welfare measures, providing support for educational equivalence, higher education, job enablers (uniform, cycles, umbrellas, bottle and bags), setting up of ASHA rest rooms at health facilities, etc. are also being offered. Punjab too is offering reservations to the ASHAs in the placement for the posts of Auxiliary Nurse Midwives and Staff Nurse; however, the awareness among ASHAs regarding this was absent [6].

The shortage of human and physical infrastructure at government hospitals acts as a barrier to the functioning of CHWs, and the apathetic behavior of the hospital staff with pregnant women threatens the credibility of these workers, who motivate people to utilize the services of public hospitals. The most important predictor of satisfaction with the quality of healthcare in government facilities was the provider's behavior in terms of respect and politeness [29].

\section{Conclusion}

The ASHAs in India can be attributed for bringing a turnaround in the health scenario of the country. The utilization of maternal health services has witnessed marked improvements as a 
JHR

36,2

262

result of the laborious efforts of these workers. Performing an interminable list of tasks, including being the spokesperson of government before elections, this pink army is the backbone of primary healthcare in India. Facing multiple odds, these workers have managed to travail in making basic healthcare accessible to those living in the margins. One key reason for the persecution of ASHA workers or the expecting women at the hands of the staff at public hospitals stems from such hospitals being overburdened, understaffed and illequipped. Along with addressing the issues of these workers, public health spending of both state and center government needs to increase. Health being a state subject in India, the state government of Punjab needs to devise a mix of monetary and nonmonetary incentives, as it is being done in other states to compensate for the efforts and time investment of these workers in a fair manner. Rather than cashing in on the status of women in the society where the opportunity to work as an ASHA provided a much-needed window to these women to step out of home, the respective governments should acknowledge the indispensable contributions made by these CHWs without whom the dream of taking healthcare to the doorstep would have crumbled.

\section{Limitations}

The study adopted a demand-side perspective while analyzing the problems being faced by CHWs in Punjab. The viewpoints of other stakeholders have not been considered.

Conflict of Interest: None

\section{References}

1. World Health Organization [WHO]. Strengthening the performance of community health workers in primary health care. Geneva: WHO; 1989.

2. Perry HB, Zulliger R, Rogers MM. Community health workers in low-, middle-, and high-income countries: an overview of their history, recent evolution, and current effectiveness. Annu Rev Public Health. 2014; 35: 399-421. doi: 10.1146/annurev-publhealth-032013-182354.

3. World Health Organization [WHO]. Treat, train, retain: the AIDS and health workforce plan. Report on the consultation on AIDS and Human Resources for Health, WHO, Geneva, 11-12, May 2006. Geneva: WHO; 2006.

4. Schneider H, Hlophe H, van Rensburg D. Community health workers and the response to HIV/ AIDS in South Africa: tensions and prospects. Health Policy Plan. 2008; 23(3): 179-87. doi: 10.1093/ heapol/czn006.

5. Government of India. National rural health mission: meeting people's health needs in rural area framework for implementation 2005-2012. [updated 2020 April 7; cited 2020 April 7]. Available from: https://nhm.gov.in/index4.php?lang =1\&level=0\&linkid=452\&lid=138.

6. Government of India, Ministry of Health and Family Welfare, National Health Mission. Update on ASHA programme. New Delhi: Ministry of Health and Family Welfare; 2019.

7. Government of India, Ministry of Health and Family Welfare, National Health Mission. About accredited social health activist (ASHA). [updated: 2020 April 7; cited 2020 April 7]. Available from: https://nhm.gov.in/index1.php?lang =1\&level=1\&sublinkid=150\&lid=226.

8. Sharma R, Webster P, Bhattacharyya S. Factors affecting the performance of community health workers in India: a multi-stakeholder perspective. Glob. Health Action. 2014; 7: 25352. doi: 10.3402/ gha.v7.25352.

9. Delhi, Punjab are richest states. All about the latest wealth index. India Today [Internet]. 2018 [cited 2020 April 7]. Available from: https://www.indiatoday.in/education-today/gk-current-affairs/ story/delhi-punjab-are-richest-states-all-about-the-latest-wealth-index-1145618-2018-01-15.

10. India, Office of the Registrar General. Special bulletin on maternal mortality in India (2014-16; 2015-17; and 2016-18). New Delhi: Office of the Registrar General; [n.d.]. 
11. Singh H. Punjab's mother mortality ratio declines, among bottom 3 in country. Hindustan Times [Internet]. 2020 July 17 [cited 2020 July 29]. Available from: https:/www.hindustantimes.com/ cities/punjab-s-mother-mortality-ratio-declines-among-bottom-3-in-country/story-XCtgwjQRG0 HUJ1g8z12huL.html.

12. Ministry of Health and Family Welfare. Janani Suraksha Yojana: features and frequently asked questions and answers. [updated 2006 October; cited 2020 April 7]. Available from: https://mohfw. gov.in/sites/default/files/FEATURES\%20FREQUENTLY\%20ASKED\%20QUESTIONS.pdf.

13. Lim SS, Dandona L, Hoisington JA, James SL, Hogan MC, Gakidou E. India's Janani Suraksha Yojana, a conditional cash transfer programme to increase births in health facilities: an impact evaluation. Lancet. 2010; 375(9730): 2009-23. doi: 10.1016/S0140-6736(10)60744-1.

14. Panja TK, Mukhopadhyay DK, Sinha N, Saren AB, Sinhababu A, Biswas AB. Are institutional deliveries promoted by Janani Suraksha Yojana in a district of West Bengal, India?. Indian J Public Health. 2012; 56(1): 69-72. doi: 10.4103/0019-557x.96980.

15. Goel S, Sharma D, Rani S. Factors influencing Janani Suraksha Yojana utilization in a Northern city of India. Int J Reprod Contracept Obstet Gynecol. 2017; 6(2): 575-9. doi: 10.18203/2320-1770. ijrcog20170385.

16. International Institute of Population Sciences [IIPS]. National family health survey-4 (2015-16): state fact sheet Punjab. Mumbai: IIPS; 2017.

17. Singh MK, Singh J, Ahmad N, Kumari R, Khanna A. Factors influencing utilization of ASHA services under NRHM in relation to maternal health in rural Lucknow. Indian J Community Med. 2010; 35(3): 414-9. doi: 10.4103/0970-0218.69272.

18. Agarwal S, Curtis SL, Angeles G, Speizer IS, Singh K, Thomas JC. The impact of India's accredited social health activist (ASHA) program on the utilization of maternity services: a nationally representative longitudinal modelling study. Human Resources for Health. 2019; 17(1): 68. doi: 10. 1186/s12960-019-0402-4.

19. ET Bureau. Government panel for raising minimum wage to Rs. 375. The economic times [Internet]. 2019 February 14 [cited 2020 April 7]. Available from: https://economictimes.indiatimes. com/news/economy/policy/government-panel-for-raising-minimum-wage-to-rs-375/articleshow/ 67999599.cms?from $=$ mdr.

20. Ormel H, Kok M, Kane S, Ahmed R, Chikaphupha K, Rashid SF, et al. Salaried and voluntary community health workers: exploring how incentives and expectation gaps influence motivation. Human Resources for Health. 2019; 17(1): 59. doi: 10.1186/s12960-019-0387-z.

21. Bajpai N, Dholakia RH. Improving the performance of accredited social health activists in India. Working paper no. 1. Mumbai: Columbia Global Centers, South Asia Columbia University; 2011.

22. Scott K, Shanker S. Tying their hands? Institutional obstacles to the success of the ASHA community health worker programme in rural north India. AIDS Care. 2010; 22(Suppl 2): 1606-12. doi: 10.1080/09540121.2010.507751.

23. Saprii L, Richards E, Kokho P, Theobald S. Community health workers in rural India: analysing the opportunities and challenges accredited social health activists (ASHAs) face in realising their multiple roles. Human Resources for Health. 2015; 13: 95. doi: 10.1186/s12960015-0094-3.

24. Bhatia K. Performance-based incentives of the ASHA scheme: stakeholders' perspectives. Econ Polit Wkly. 2014; 49(22): 145-151.

25. Kammowanee R. ASHAs' health services-Social service or care work?. Econ Polit Wkly. 2019; 54(49): 12-15.

26. Bhattacharyya K, Winch P, LeBan K, Tien M. Community health worker incentives and disincentives: how they affect motivation, retention, and sustainability. Arlington, Virginia: Basic Support for Institutionalizing Child Survival Project (BASICS II) for the United States Agency for International Development; 2011.

Community health workers in rural Punjab 
27. Rahman SM, Ali NA, Jennings L, Seraji MHR, Mannan I, Shah R, et al. Factors affecting recruitment and retention of community health workers in a newborn care intervention in Bangladesh. Human Resources for Health. 2010; 8(1): 12. doi: 10.1186/1478-4491-8-12.

28. World Health Organization [WHO]. WHO guideline on health policy and system support to optimize community health worker programmes. Geneva: WHO; 2018.

29. Mendoza Aldana J, Piechulek H, al-Sabir A. Client satisfaction and quality of health care in rural Bangladesh. Bull World Health Organ. 2001; 79(6): 512-7.

\section{Corresponding author}

Niharika Mahajan can be contacted at: niharika.mahajan02@gmail.com

For instructions on how to order reprints of this article, please visit our website: 